\title{
Influence of electrode separation on electrical treeing in a glassy epoxy resin
}

DOI:

10.1109/CEIDP.2017.8257519

\section{Document Version}

Accepted author manuscript

Link to publication record in Manchester Research Explorer

\section{Citation for published version (APA):}

Zheng, H., Rowland, S., \& Jiang, N. (2018). Influence of electrode separation on electrical treeing in a glassy epoxy resin. In IEEE Conference on Electrical Insulation and Dielectric Phenomena (CEIDP)

https://doi.org/10.1109/CEIDP.2017.8257519

\section{Published in:}

IEEE Conference on Electrical Insulation and Dielectric Phenomena (CEIDP)

\section{Citing this paper}

Please note that where the full-text provided on Manchester Research Explorer is the Author Accepted Manuscript or Proof version this may differ from the final Published version. If citing, it is advised that you check and use the publisher's definitive version.

\section{General rights}

Copyright and moral rights for the publications made accessible in the Research Explorer are retained by the authors and/or other copyright owners and it is a condition of accessing publications that users recognise and abide by the legal requirements associated with these rights.

\section{Takedown policy}

If you believe that this document breaches copyright please refer to the University of Manchester's Takedown Procedures [http://man.ac.uk/04Y6Bo] or contact uml.scholarlycommunications@manchester.ac.uk providing relevant details, so we can investigate your claim.

\section{OPEN ACCESS}




\title{
Influence of electrode separation on electrical treeing in a glassy epoxy resin
}

\author{
Hualong ZHENG, Simon M. Rowland, Ningyu JIANG \\ School of Electrical and Electronic Engineering \\ University of Manchester \\ Manchester, UK
}

\begin{abstract}
The influence of electrode separation on electrical treeing in a glassy epoxy resin of needle-plane geometry has been studied under a fixed $50 \mathrm{~Hz} \mathrm{AC}$ stress of $15 \mathrm{kV}$ peak voltage. Growth of electrical trees is compared between samples of $1 \mathrm{~mm}$, $2 \mathrm{~mm}, 4 \mathrm{~mm}$ and $6 \mathrm{~mm}$ electrode separation. The tree inception times and their distributions imply a change of mechanism for tree initiation when the electrode separation is above $4 \mathrm{~mm}$. Subsequent tree growth was not affected by electrode separation. The trees were of the filamentary non-conductive type and did not feature a classical runaway to breakdown. Rather, tree propagation along the needle axis has been found to follow a rate independent of electrode separation. This implies that the filamentary tree growth is not dominated by modification of the electrical field in front of the tree tips, although such a conclusion is in conflict with existing treeing models. Breakdown does not occur rapidly after a filamentary tree fully crosses the dielectric, but is still primarily determined by the average electrical field across the sample.
\end{abstract}

Keywords-Electrical tree, epoxy resin, electrode distance.

\section{INTRODUCTION}

In solid polymeric dielectrics, electrical treeing is a slow deterioration process which can eventually lead to insulation failure (breakdown). To study the mechanisms of electrical tree initiation and propagation, laboratory experiments normally employ artificial field-enhancing defects (for instance metallic or air projections) to accelerate the treeing process so that it can be observed within a reasonable period of time. However, there is no universally adopted sample geometry for studying tree growth in the laboratory. Samples of different geometries can be found in literature [1], for example the needle-needle, needle-hemisphere [2], needle-plane and wire-plane geometries [3]. The needle and wire electrodes are usually a few micrometers in radius and the electrode separation varies, for instance, from $1 \mathrm{~mm}$ to $5 \mathrm{~mm} \mathrm{[4]} \mathrm{[5]} \mathrm{[6].}$

Since tree initiation is believed to be primarily dominated by the maximum electrical field at the field-enhancing electrode, more attention has been paid to controlling and studying the radius of the sharp electrode tip, for example in [7], rather than the electrode separation. The latter is a secondary factor in determining to the magnitude of the maximum, highly divergent local electrical field. As a result, there is a lack of experimental evidence concerning how the electrode separation affects the electrical tree growth. However this remains important in the context of applying laboratorybased conclusions to large scale commercial insulation systems.
This work reports experimental results of electrical treeing in epoxy resin samples of electrode separation between $1 \mathrm{~mm}$ and $6 \mathrm{~mm}$. The characteristics of the different treeing stages of inception, propagation and breakdown are compared.

\section{EXPERIMENTAL}

Samples of needle-plane geometry were prepared for the electrical treeing test. The epoxy resin and hardener used were Araldite ${ }^{\circledR}$ LY 5052 and Aradur ${ }^{\circledR} 5052$ (from Huntsman). Each sample was made by casting an Ogura needle into a $22 \mathrm{~mm} \times$ $22 \mathrm{~mm} \times 25 \mathrm{~mm}$ epoxy resin cuboid. The needle tip had a radius of $3 \mu \mathrm{m}$ and was separated from the opposite planar surface of the sample by $1 \mathrm{~mm}, 2 \mathrm{~mm}, 4 \mathrm{~mm}$ or $6 \mathrm{~mm}$. After room temperature curing for about 24 hours, samples were post-cured at $100^{\circ} \mathrm{C}$ for 4 hours to achieve a glass transient temperature of $120^{\circ} \mathrm{C}-134^{\circ} \mathrm{C}$ (according to the manufacture's datasheet). 6 samples were prepared for each value of electrode distance.

During the electrical treeing test, $15 \mathrm{kV}_{\mathrm{p}}$ (voltage amplitude), $50 \mathrm{~Hz}$ AC stress was applied to the needle electrode and the bottom surface of a sample was pressed onto a grounded flat brass electrode. Treeing processes were monitored through a CCD camera which recorded images of the 2-D projections of the tree structures. Tests were terminated upon sample breakdown or after a predetermined time (which varies between groups but was generally above 500 minutes).

\section{A. Inception}

\section{RESULtS}

There were two types of trees initiated after voltage application. They are visually distinct from each other in the the 2-D images in terms of the contrast / grey level of the tree structures. This arises primarily from the different radii of the constituent tree channels. For convenience these are referred to as 'PD trees' and 'filamentary trees'. The diameters of tree channels are typically larger than $10 \mu \mathrm{m}$ for PD trees and about $1 \mu \mathrm{m}$ for filamentary trees.

To assess the impact of electrode separation on tree initiation, the inception time, the time between voltage application and the formation of the first observable tree channel (either PD tree or filamentary tree), was recorded and is shown in Figure 1. Despite the poor consistency of values, the average inception time for the $6 \mathrm{~mm}$ sample group is clearly longer (at least 3 times longer) than those of the rest of samples. The majority of the $6 \mathrm{~mm}$ group took longer to initiate than all the other samples with the exception of one outlier in the $4 \mathrm{~mm}$ group. 


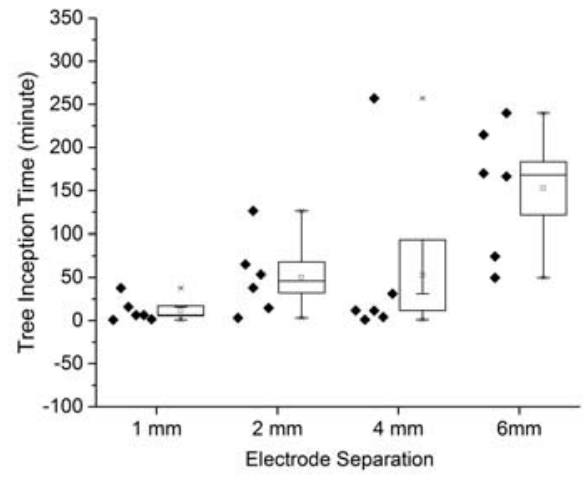

Figure 1. Box plot of tree inception times for all samples.

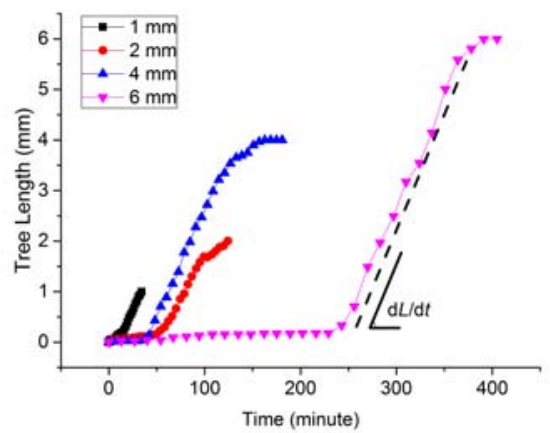

Figure 2. Examples of typical tree growth characteristics in each sample group. The samples selected for comparison all started with PD tree growth, which transformed into filamentary tree growth.

\section{B. Tree Propagation}

If the tree initiated from the needle tip is a PD tree, it typically propagates up to a few hundreds of micrometers, before slowing. Then sometime later (the time delay is affected by the electrode separation), a filamentary tree starts to grow from the furthest extent of the PD tree. If the tree initiated from the needle tip is a filamentary tree, it continuously propagates until reaching the plane ground electrode. Typical tree propagation characteristics for each sample group are shown in Figure 2, which shows the tree lengths $L$ (the distance between needle tip and the tree tip along the needle axis) as a function of time. All 4 samples shown in Figure 2 initially started with PD tree inception. Taking the $6 \mathrm{~mm}$ sample as an example, after the PD tree initiated, it barely grew in the following 240 minutes. The rapid linear increase in tree length from about 240 minutes is a result of filamentary tree extension. For samples without PD tree inception (i.e. those which started in the filamentary form), only the rapid growth of a filamentary tree can be observed. Apart from $1 \mathrm{~mm}$ samples, the tree growth rates reduced when approaching the plane electrode. As a result, and considering the different stages in the treeing process, the overall tree propagation time (from inception to reaching the counter electrode) cannot alone characterize a filamentary tree's growth.

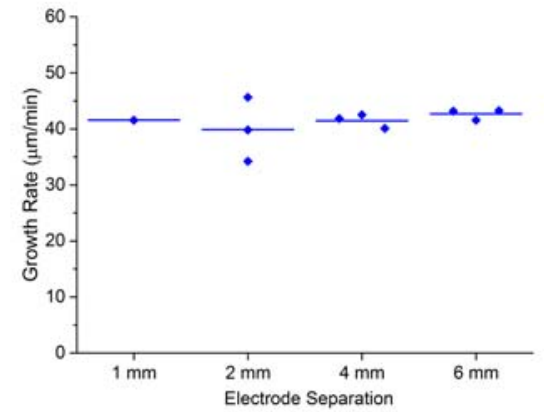

Figure 3. Growth rates of filamentary trees estimated from the time dependent tree length curves for representative samples in each group. The rates shown are taken form the linear periods of tree propagation. The solid lines indicate the average value for data points.

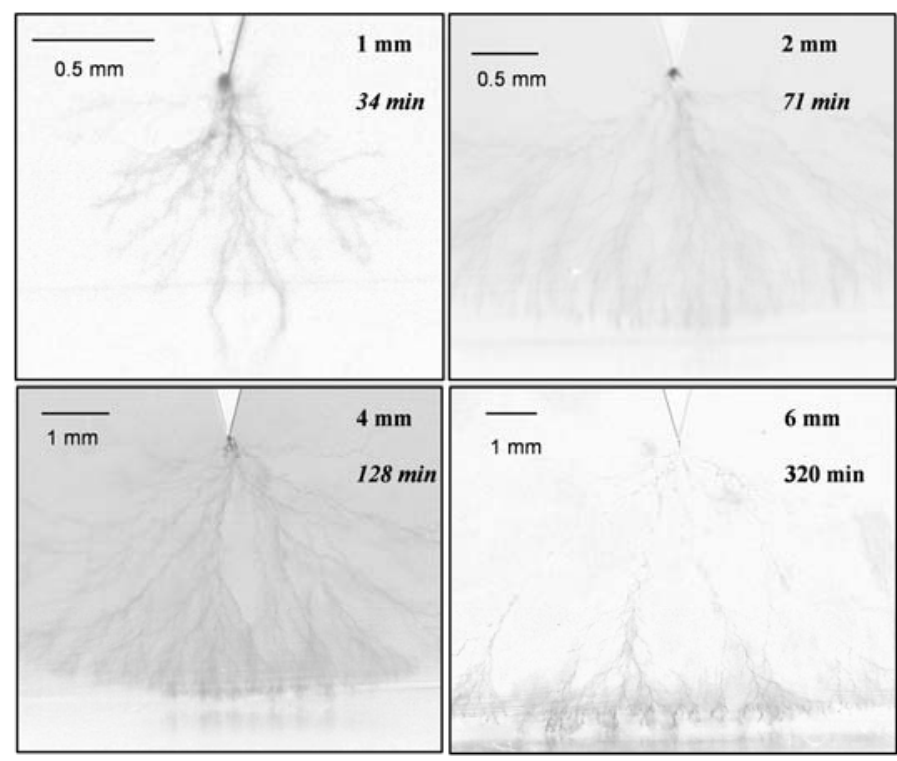

Figure 4. Typical shapes of electrical trees grown in each sample group at the time of reaching the plane electrode. The background image at time 0 was subtracted.

To quantify the filamentary tree growth, the mean growth rates $(\mathrm{dL} / \mathrm{dt})$ were obtained from the slopes of the linear growth periods in the measured tree length growth curves. The average filamentary tree propagation rates for each sample group are compared in Figure 3. Not all samples are represented in this comparison. Samples in which trees did not initiate at the needle tip, or which had extensive initial PD tree growth (mostly in $1 \mathrm{~mm}$ samples) or poor image quality were not used. As can be seen from Figure 3, the average growth rates of filamentary trees are the same between samples of different electrode distances, despite variations between individual samples.

\section{Tree shape}

The tree structures in samples of different electrode distances are compared in Figure 4. No significant difference can be found between the tree shapes. Due to the nature of the filamentary tree whose channels are only about $1 \mu \mathrm{m}$ thick or 


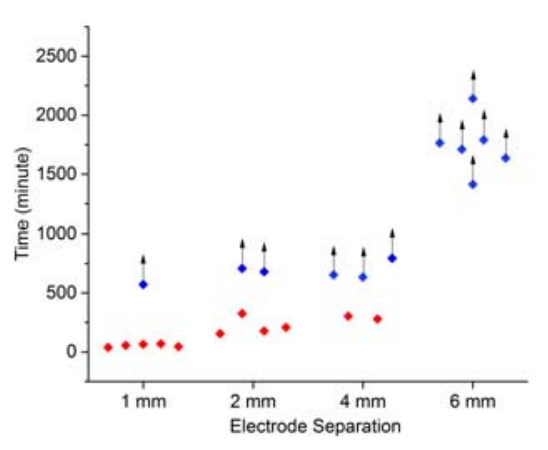

Figure 5. Time to sample breakdown. For samples that did not breakdown by the end of test, the total stressing times are given as blue points and marked with arrows.

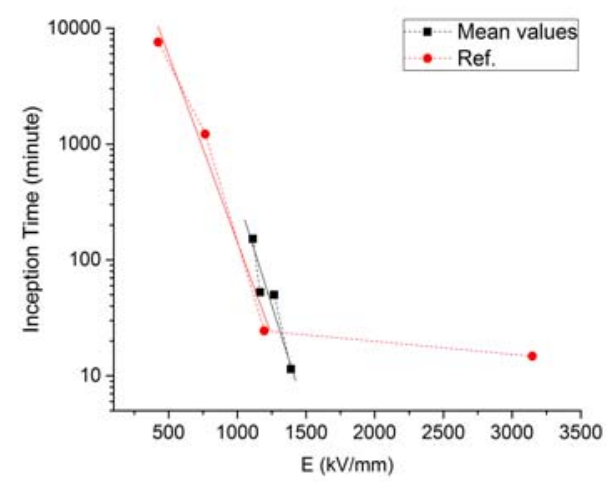

Figure 6. Tree inception times as a function of the maximum electric field at the needle tip are given alongside data estimated from the work reported in [7]. Two solid trend lines have been added for each data set.

less, it is difficult to perform meaningful quantified analysis on the tree morphology on these two-dimensional images.

\section{Breakdown}

Breakdown did not necessarily occur immediately after a filamentary tree propagated across to the planar surface of a sample. The lifetime of failed samples (the time to break down from voltage application) or, if they did not fail, the total testing time are plotted in Figure 5. The proportion of samples which broke down decreased with an increase of electrode separation. Five out of six $1 \mathrm{~mm}$ samples failed, but no $6 \mathrm{~mm}$ sample failed after extended testing.

\section{DISCUSSION}

\section{A. Tree Inception}

\section{A-1 Initiation time as a function of electrical field}

Since the tree inception is believed to be dominated by the local electrical field at the needle tip, the mean values of the tree inception time in Figure 1 are plotted against the maximum electrical field at the needle tip in Figure 6. Here the maximum electrical field at the needle tip is calculated based on Mason's equation [8]: where $V$ is the peak voltage applied to the needle electrode, $r$ is the radius of the needle tip, $d$ is the distance between the tip and the planar surface. In addition, data is added from the experimental results in [7] which compares the tree inception time with different needle tip radii at $10 \mathrm{kV}$ rms AC using needle-plane samples and a $2 \mathrm{~mm}$ electrode gap. The two parallel trend lines in the semi-log plot suggest an approximate exponential decay of the tree inception time with the increase of $\mathrm{E}_{\max }$ and good consistancy between the datasets.

\section{A-2 Weibull Statistic}

For each sample group, the inception time was analyzed using the two parameter Weibull probability distribution. The shape parameters were directly calculated using Matlab functions, whilst detailed methods of calculation can be found elsewhere, for example in [9].

The dimensionless shape parameters along with their $90 \%$ confidence limits are plotted against the calculated $\mathrm{E}_{\max }$ in Figure 7. For $1 \mathrm{~mm}, 2 \mathrm{~mm}$ and $4 \mathrm{~mm}$ samples, the shape parameters are similar and close to 1 . It means that for these samples the likelihood of tree inception does not change significantly with time. However a higher shape parameter of about 2.4 was estimated for $6 \mathrm{~mm}$ samples. With a shape parameter larger than 2, the likelihood of tree inception increases with time at a growing rate. This implies that a degradation mechanism favoring tree initiation was occurring at the needle tip at the lower fields of the $6 \mathrm{~mm}$ sample. With the accumulative degradation, it becomes more likely for the tree to incept as time passes. Under a higher field, however, this degradation may be overridden by a stronger short term random 'local breakdown mechanism'. According to Figure 7, a threshold between the rapid and slow degradation mechanisms can be found at round $1140 \mathrm{kV} / \mathrm{mm}$.

\section{B. Tree Propagation}

There is a major difference between the filamentary tree propagation and classical treeing, which is that the filamentary tree did not feature a runaway to breakdown. Instead, when approaching the counter electrode, the growth rate of a filamentary tree was observed to slow down for $2 \mathrm{~mm}, 4 \mathrm{~mm}$ and $6 \mathrm{~mm}$ samples. However this decelerated growth stage was not observed for $1 \mathrm{~mm}$ samples, most of which broke down immediately the tree crossed the dielectric. The origin of this decelerated growth stage has been discussed elsewhere [15]. In brief, it is mainly attributed to the inhomogeneous properties of the sample after being exposed to the ambient conditions (for instance moisture). As a consequence, the mean growth rate during a stable growth period is more appropriate for characterizing the filamentary tree propagation than the total time elapsed.

As shown in Figure 3, a similar growth rate has been found for filamentary trees in samples of all electrode distances, whether or not incepted at a needle tip or from the PD tree tips. This suggests that the dominating mechanism for the filamentary tree propagation is independent of the electrode distance. Nevertheless such tree

$$
E_{\max }=\frac{2 V}{r \ln (1+4 d / r)}
$$




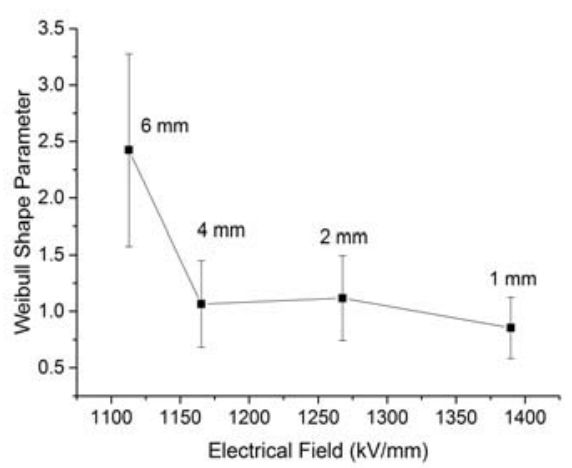

Figure 7. Weibull shape parameters of the tree inception time distributions as a function of the maximum electrical field at the needle tip. Error bars show the $90 \%$ confidence limits.

growth does not fit with any field-driven models in which the Laplacian field at the tree tips is a critical parameter determining directly [10] or indirectly [11] [12] [13] [14] new tree channel formation.

\section{Breakdown}

As shown in Figure 5, samples with filamentary trees which have fully traversed the sample could still maintain dielectric integrity. Most $1 \mathrm{~mm}$ samples broke down immediately once a tree channel reached the counter electrode, while the $6 \mathrm{~mm}$ samples could withstand the applied stress for a considerable time. For those that did not immediately breakdown, the lifetime was determined by trees subsequently growing back from the planar electrode to the needle electrode. This has been introduced as reverse treeing in [15]. Based on the rates of breakdown occurrence in Figure 5, the lifetime of an insulation subjected to the filamentary tree degradation can be regarded as being dominated by the average electrical field applied.

\section{CONCLUSION}

With a constant AC voltage applied, tree inception mechanisms in needle-plane samples are affected by the insulation thickness, i.e. the electrode separation and a threshold was found between $4 \mathrm{~mm}$ and $6 \mathrm{~mm}$. The inception times for samples of $6 \mathrm{~mm}$ electrode separation are much longer than that of the $1 \mathrm{~mm}, 2 \mathrm{~mm}$ and $4 \mathrm{~mm}$ samples. Moreover Weibull analysis shows that tree inception rates for $1 \mathrm{~mm}, 2 \mathrm{~mm}$ and $4 \mathrm{~mm}$ sample are relatively constant in time (Weibull shape parameters are around 1). Whereas a higher Weibull shape parameter of about 2.4 determined for $6 \mathrm{~mm}$ samples suggests a progressive deterioration which creates favourable conditions for tree inception and consequently an increase the likelihood of tree inception with time.

Even in situations where classic thick channel PD trees developed at tree inception, it was filamentary trees consisting of finer channels, which traversed the majority of the insulation. The mean growth rates determined have been used to characterize the filamentary treeing. The growth rates of filamentary trees were found to be similar among samples of various electrode distances. This implies that the mechanisms controlling the filamentary tree extension are not driven by modification of the field at the tree tip, a finding which conflicts with some existing treeing models.
The dielectric can withstand the applied voltage during growth of the filamentary tree and for some time even after it has traversed the insulation, suggesting the tree is insulating. The time to final breakdown of the sample is determined by the average electrical field, and so is dependent on electrode separation.

\section{ACKNOWLEDGMENT}

The authors are grateful to the EPSRC for the financial support of this work through the project 'Towards Enhanced HVDC Cable Systems', EP/L021560/1

\section{REFERENCES}

[1] J. H. Mason, "Assessing the resistance of polymers to electrical treeing," Physical Science, Measurement and Instrumentation, Management and Education - Reviews, IEE Proceedings A, vol. 128, pp. 193-201, 1981.

[2] N. Yoshimura, S. Fujita, and F. Noto, "Comparison of Single and Double Needle Tests for Evaluation of Resistance to Treeing Breakdown," IEEE Transactions on Electrical Insulation, vol. EI-18, pp. 42-47, 1983.

[3] E. M. Jarvid, A. B. Johansson, J. H. M. Blennow, M. R. Andersson, and S. M. Gubanski, "Evaluation of the performance of several object types for electrical treeing experiments," Dielectrics and Electrical Insulation, IEEE Transactions on, vol. 20, pp. 1712-1719, 2013.

[4] H. Mitsui, T. Yoshimitsu, Y. Mizutani, and K. Umemoto, "Electrical Failure Properties of Cast Epoxy Resins," IEEE Transactions on Electrical Insulation, vol. EI-16, pp. 533-542, 1981.

[5] E. J. McMahon, "A Tutorial on Treeing," Electrical Insulation, IEEE Transactions on, vol. EI-13, pp. 277-288, 1978.

[6] K. Nakanishi, S. Hirabayashi, and Y. Inuishi, "Phenomena and Mechanisms of Tree Inception in Epoxy Resins," Electrical Insulation, IEEE Transactions on, vol. EI-14, pp. 306-314, 1979.

[7] D. W. Auckland, J. M. Cooper, and B. R. Varlow, "Factors affecting electrical tree testing," Science, Measurement and Technology, IEE Proceedings A, vol. 139, pp. 9-13, 1992.

[8] J. H. Mason, "Breakdown of Solid Dielectrics in Divergent Fields," Proceedings of the IEE - Part C: Monographs, vol. 102, pp. 254-263, 1955.

[9] L. A. Dissado and J. C. Fothergill, Electrical Degradation and Breakdown in Polymers: Institution of Engineering and Technology, 1992.

[10] J. V. Champion, S. J. Dodd, and G. C. Stevens, "Analysis and modelling of electrical tree growth in synthetic resins over a wide range of stressing voltage," Journal of Physics D: Applied Physics, vol. 27, p. 1020, 1994.

[11] J. C. Fothergill, L. A. Dissado, and P. J. J. Sweeney, "A dischargeavalanche theory for the propagation of electrical trees. A physical basis for their voltage dependence," Dielectrics and Electrical Insulation, IEEE Transactions on, vol. 1, pp. 474-486, 1994.

[12] L. A. Dissado, S. J. Dodd, J. V. Champion, P. I. Williams, and J. M. Alison, "Propagation of electrical tree structures in solid polymeric insulation," Dielectrics and Electrical Insulation, IEEE Transactions on, vol. 4, pp. 259-279, 1997.

[13] S. J. Dodd, "A deterministic model for the growth of non-conducting electrical tree structures," Journal of Physics D: Applied Physics, vol. 36, p. 129, 2003.

[14] M. D. Noskov, A. S. Malinovski, M. Sack, and A. J. Schwab, "Modelling of partial discharge development in electrical tree channels," IEEE Transactions on Dielectrics and Electrical Insulation, vol. 10 , pp. 425-434, 2003.

[15] I. Iddrissu, Z. Lv, S. M. Rowland, "The dynamic character of partial discharge in epoxy resin at different stages of treeing" IEEE International Conference on Dielectrics (ICD), Montpellier, Vol. 2, pp. $728-731,2016$ 